\title{
Targeting neuronal populations of the striatum
}

\author{
Pierre F. Durieux, Serge N. Schiffmann and Alban de Kerchove d'Exaerde*
}

Laboratory of Neurophysiology, School of Medicine, Université Libre de Bruxelles, Brussels, Belgium

\section{Edited by:}

Emmanuel Valjent, Université

Montpellier 1 and 2, France

Reviewed by:

Charles R. Gerfen, National Institutes of Health, USA

Helen Bateup, Harvard Medical

School, USA

\section{*Correspondence:}

Alban de Kerchove d'Exaerde,

Laboratory of Neurophysiology,

Université Libre de Bruxelles,

Campus Erasme CP 601, Building C

Room 3.145, 808 Route de Lennik,

B-1070 Brussels, Belgium.

e-mail: adekerch@ulb.ac.be
The striatum is critically involved in motor and motivational functions. The dorsal striatum, caudate-putamen, is primarily implicated in motor control and the learning of habits and skills, whereas the ventral striatum, the nucleus accumbens, is essential for motivation and drug reinforcement. The GABA medium-sized spiny neurons (MSNs, about $95 \%$ of striatal neurons), which are targets of the cerebral cortex and the midbrain dopaminergic neurons, form two pathways. The dopamine $D_{1}$ receptor-positive $\left(D_{1} R\right)$ striatonigral MSNs project to the medial globus pallidus and substantia nigra pars reticulata (direct pathway) and co-express $D_{1} R$ and substance $P$, whereas dopamine $D_{2}$ receptor-positive $\left(D_{2} R\right)$ striatopallidal MSNs project to the lateral globus pallidus (indirect pathway) and co-express $D_{2} R$, adenosine $A_{2 A}$ receptor $\left(A_{2 A} R\right)$ and enkephalin (Enk). The specific role of the two efferent pathways in motor and motivational control remained poorly understood until recently. Indeed, $D_{1} R$ striatonigral and $D_{2} R$ striatopallidal neurons, are intermingled and morphologically indistinguishable, and, hence, cannot be functionally dissociated with techniques such as chemical lesions or surgery. In view of the still debated respective functions of projection $D_{2} R$ striatopallidal and $D_{1} R$ striatonigral neurons and striatal interneurons, both in motor control and learning but also in more cognitive processes such as motivation, the present review sum up the development of new models and techniques (bacterial artificial chromosome transgenesis, optogenetic, viral transgenesis) allowing the selective targeting of these striatal neuronal populations in adult animal brain to understand their specific roles.

\section{Keywords: striatum, medium-sized spiny neurons, interneurons, transgenesis, BAC}

\section{INTRODUCTION}

The striatum represents the main input nucleus of the basal ganglia, a system of subcortical nuclei critically involved in motor control and motivational processes and altered in several conditions such as Parkinson's and Huntington's diseases or drug addiction and schizophrenia (Nestler, 2005; Graybiel, 2008; Kreitzer and Malenka, 2008). The projection neurons of the striatum are GABAergic ( $\gamma$-aminobutyric acid) medium-sized spiny neurons (MSNs), which account for the large majority of striatal neurons (95\% in rodents; Tepper et al., 2007). The MSNs are subdivided into two subpopulations that form two main efferent pathways. The striatonigral MSNs mainly project to the entopeduncular nucleus (EP or medial globus pallidus) and substantia nigra pars reticulata $\mathrm{SNr}$ (direct pathway) and express dopamine $\mathrm{D}_{1}$ receptor $\left(\mathrm{D}_{1} \mathrm{R}, d r d 1 a\right), \mathrm{M} 4$ muscarinic acetylcholine receptor (chrm4) and substance P neuropeptide (SP) whereas striatopallidal MSNs mostly project to the lateral globus pallidus (LGP; indirect pathway) and co-express dopamine $\mathrm{D}_{2}$ receptor $\left(\mathrm{D}_{2} \mathrm{R}\right.$, $d r d 2$ ), adenosine $\mathrm{A}_{2 \mathrm{~A}}$ receptor $\left(\mathrm{A}_{2 \mathrm{~A}} \mathrm{R}\right)$ and enkephalin (Enk; Young and Bonner, 1986; Gerfen et al., 1990; Graybiel, 1990; Schiffmann and Vanderhaegen, 1993). Striatal interneurons, which account for a small proportion of striatal neurons $(2-3 \%$ in rodent and possibly up to $20 \%$ in primates; Tepper and Bolam, 2004), are phenotypically diverse and consist of four different populations: one cholinergic and three GABAergic. The cholinergic interneurons are giant aspiny neurons (with a somatic diameter that can be in excess of $40 \mu \mathrm{m}$ ) expressing the choline acetyltransferase (ChAT; Kawaguchi et al., 1995). The three subtypes of GABAergic interneurons can be distinguished neurochemically: two express either the calcium binding protein parvalbumin or calretinin, and one co-expresses the peptides somatostatin and neuropeptideY (NPY) as well as the enzyme neuronal nitric oxide synthase (nNOS; Tepper and Bolam, 2004). Based on the origin of cortical glutamatergic and midbrain dopaminergic (DA) afferents, the striatum can be functionally divided into dorsal and ventral subregions. The dorsal striatum is thought to be involved mostly in motor behaviors, while ventral striatum (or nucleus accumbens, NAc) is crucial for motivational processes (Robbins and Everitt, 1996; Groenewegen, 2003; Nestler, 2005).

The striatal neurons are mosaically distributed through all the striatum (Bolam et al., 2000) and cannot be targeted with techniques such as electrolysis or surgery. Selective modulations of striatal subpopulation activity by drugs remains difficult since most of pharmacological agents have multiple targets widely distributed in the brain. Moreover, striatal MSNs are similar in number, in size, and shape. Because of these technical limitations, the deciphering of striatum cell-type specific functions remained unsatisfactory for decades. In this paper, we will review the different strategies developed to target intrinsic striatal neuronal subtypes, with an emphasis on the most recent state of the art genetic tools and the major functional processes illuminated in these models. 


\section{FIRST EXPERIMENTAL TOOLS TO TARGET STRIATAL SUBPOPULATIONS}

Because striatal neuronal types differ one from each other notably according to their gene expression pattern, expression of a particular gene can lead to selective susceptibility to a given pharmacological agent. Then, initial approaches attempting to target neuronal population in the striatum consisted in using toxic compound with a relative specificity for a neuronal subtype in wildtype animals. For instance, stereotaxic injection of the aziridinium ion of ethylcholine (AF64A; Mantione et al., 1981) in the rat striatum led to a desired and expected decrease in ChAT activity but with a concomitant loss of glutamate decarboxylase (GAD) and tyrosine hydroxylase (TH) activities (Sandberg et al., 1984), suggesting a toxic effect against striatal cholinergic neurons as well as other neuronal populations. Intraventricular administration of an immunotoxin composed of a monoclonal antibody directed to the low-affinity rat nerve growth factor (NGF) receptor (192 IgG) chemically linked to the ribosome inactivating protein saporin (192 IgG-saporin; Wiley et al., 1991) was shown to destroy cholinergic neurons in the basal forebrain but not in the striatum, perhaps due to the low NGF receptor expression level in the latter cells (Book et al., 1992; Leanza et al., 1995). A similar immunotoxin-based strategy was developed to target striatal neurons expressing high levels of tachykinin (NK-1) receptor, ablating both NPY and ChAT expressing striatal interneurons (Saka et al., 2002).

In other experiments, neurotoxic non-selective agents were injected in target nuclei of the striatum efferent populations (i.e., the $\mathrm{SNr}$ or the LGP) to selectively kill the striatonigral or the striatopallidal neurons by axonal transport (Harrison et al., 1990; Hervé et al., 1993; Roberts et al., 1993). While this strategy can lead to modest reduction of striatopallidal or striatonigral neuron number (Roberts et al., 1993), it lacks striatum specificity since the neurotoxin can be axonally transported from the injection site to multiple areas.

To target a specific neuronal population, either to ablate these cells or to inactivate a specific gene within them, the genetic targeting is the most promising approach given the large number of available tools (inducible systems, specific recombination) and regulatory sequences. The first success to target a striatal cell population by classical additional transgenesis was obtained by Nestler and colleagues (Chen et al., 1998) on the striatonigral neurons using a 1.8-kb fragment of the NSE (neuronal specific enolase) promoter to express the tetracycline transactivator (tTA) of the tetracycline (Tet) system. The Tet system is based on two elements. On one hand, the transcriptional transactivator tTA (tetracycline transactivator) is under the control of a cell-specific promoter. On the other hand, the gene necessary to affect the target neuronal population is under the control of the TRE (tetracycline-responsive element) promoter that binds tTA and will be, therefore, regulated by the presence or absence of tetracycline (Gossen and Bujard, 2002). Despite the fact that NSE is not specifically expressed in striatonigral neurons, 1 the 12 lines obtained, the line A, expressed tTA in these neurons. The specificity of this cell expression pattern is due to the insertion site of the transgene in the genome. Using this transgenic line,
Nestler and colleagues have demonstrated that overexpression of the transcription factor $\Delta F$ osB in striatonigral neurons increases the responsiveness of mice to the rewarding effect of cocaine (Kelz et al., 1999; Colby et al., 2003) as well as the rewarding effect and physical dependence to morphine (Zachariou et al., 2006).

The second striatal cell population successfully targeted by classical additional transgenesis were the cholinergic interneurons. Nakanishi and colleagues ablated them by immunotoxin-mediated cell targeting (IMTC) which allows a conditional and time controlled destruction of neurons (Kaneko et al., 2000). A transgene was made containing the alpha subunit of human interleukin-2 receptor (hIL-2R $\alpha$ ) under the control of the mouse $18.3 \mathrm{~kb} \mathrm{5}$ upstream genomic sequence containing the first and second exons of the mGluR2 gene. Out of the 14 transgenic lines obtained, two lines (IG16 and IG17) expressed hIL-2R $\alpha$ specifically in striatal cholinergic interneurons (Kaneko et al., 2000). The ablation of these cholinergic interneurons was achieved by means of the stereotaxic injection of a monoclonal antibody against hIL-2R $\alpha$ fused with a truncated Pseudomonas exotoxin. The study of these mice unraveled the concerted and adapted interactions between acetylcholine and dopamine transmissions in the basal ganglia during motor behavior (Kaneko et al., 2000) the cocaine-elicited behavior (Hikida et al., 2001) and procedural learning (Kitabatake et al., 2003).

\section{KNOCK-IN STRATEGIES}

The most accurate method to preserve all regulatory elements and sequences allowing the exact spatial-temporal expression of a gene is to insert a transgene into the native locus of the gene of interest by homologous recombination (Knock-in). Again, the first population targeted by this method were the striatonigral neurons. A transgene composed of a LoxP-NEO/STOP-LoxP cassette and the diphtheria toxin A-chain gene was inserted into the drdla gene (Drago et al., 1998). After crossing these knock-in mice with EIIa/Cre mice, expressing Cre recombinase in the fertilized oocyte, the resulting pups express the diphtheria toxin A-chain under the control of drdla promoter. Although most pups died in the first postnatal week, some mice survived to P19 and displayed bradykinesia, dystonia and reduced striatal volume. These mice did not express $D_{1} R$, substance $P$ and dynorphin mRNAs in the striatum but had normal levels of $\mathrm{D}_{2} \mathrm{R}$ and enkephalin mRNAs (Drago et al., 1998). To circumvent the short lifespan and potential developmental compensation of these mice, Drago and colleagues (Gantois et al., 2007) crossed the knock-in mice with calcium/calmodulin-dependent protein kinase II a/Cre mice (Casanova et al., 2001). The resulting mice express Cre in the forebrain starting from 1 to 2 weeks after birth. These mice are viable and displayed, among other, hindlimb dystonia and locomotor hyperactivity. An important limitation of these mice to decipher the role of the striatonigral neurons results from the destruction of other populations of neurons expressing $d r d 1 a$ in the forebrain (Weiner et al., 1991).

Palmiter's group targeted the expression of Cre recombinase in $d r d 1$ a neurons by a knock-in strategy by insertion in the $d r d 1 a$ loci (Heusner et al., 2008). These drd1a-Cre knock-in mice have 
been crossed with Gad1 floxed mice to selectively reduce GABA synthesis in striatonigral neurons (Heusner et al., 2008). The resulting mice showed altered motor skill learning in some behavioral test such as rotarod (Heusner et al., 2008). Using the same knock-in mice, this group inactivated the NR1 subunit of the glutamate NMDA receptor in $d r d 1 a$ neurons and demonstrated the impairment of amphetamine sensitization and conditioned place preference (CPP) in the mutant mice (Beutler et al., 2011). To decipher the role of these neurons in amphetamine-induced plastic phenomena and to bypass the fact that $d r d 1 a$ gene is not only expressed in striatonigral neurons they re-expressed NR1 selectively in the $d r d 1 a$ neurons of the NAc by Cre/lox viral strategy. NR1 re-expression rescued amphetamine sensitization, demonstrating that striatonigral neurons in the NAc are sufficient to retain this behavioral effect (Beutler et al., 2011).

An IMTC (see above) of striatal $d r d 2$ neurons has been undertaken by a knock-in strategy in $d r d 2$ loci (Sano et al., 2003). One week after intrastriatal immunotoxin treatment and ablation of $d r d 2$ striatal neurons, mice had spontaneous hyperactivity (Sano et al., 2003). However, $d r d 2$ is expressed not only in striatopallidal neurons but also in striatal cholinergic interneurons and in dopaminergic neurons of the SNc and VTA projecting to striatal regions (Weiner et al., 1991). In this model, the intrastriatal injection of the immunotoxin preserved the DA neurons and destroyed the striatopallidal neurons and cholinergic interneurons (Sano et al., 2003).

Knock-in parvalbumin (PV)-Cre mice were generated by insertion of an internal ribosome entry site (IRES)-Cre cassette $3^{\prime}$ to the translational stop codon of the Pvalb locus allowing a bicistronic translation (Hippenmeyer et al., 2005). Striatal Cre recombinase expression in these Pvalb-IRES-Cre mice was not described (Hippenmeyer et al., 2005), but preliminary results obtained with a LacZ reporter strain (Soriano, 1999) indicate a very low colocalization of PV immunostaining and LacZ expression (PFD et al., unpublished data). More recently, Madisen et al. (2009) generated a Pvalb-2A-Cre knock-in line with a $2 A$-Cre sequence (mediating bicistronic translation in a mechanism different from the IRES) inserted $3^{\prime}$ to the PV stop codon. While Pvalb-2A-Cre mice, as compared to Pvalb-IRES-Cre mice, exhibited higher level of Cre recombination in brain areas such as cerebral cortex or thalamus, Cre recombination in the striatum was not investigated (Madisen et al., 2009).

While the knock-in strategy is the best strategy to mimic the exact expression of a gene, it has the potentially important limitation that the insertion of the transgene causes the loss of one of the two loci of the target gene. In fact, there are several reports on the effects of $d r d 1 a$ or $d r d 2$ heterozygosity. For example, acoustic startle reactivity (Ralph-Williams et al., 2002) and dopamine-elicited late-phase LTP and facilitation of the LTD in the medial prefrontal cortex are significantly altered in $d r d 1 a+/-$ mice (Huang et al., 2004). In the case of $d r d 2$, locomotor activity is determined by gene dosage (Kelly et al., 1998) and non-selective attention is different in $d r d 2+/-$ and $d r d 2+/+$ mice (Vallone et al., 2002).

\section{BAC STRATEGIES}

In late 1990s, the possibility to manipulate bacterial artificial chromosome (BAC) containing large fragments of genomic mouse
DNA (100-250 kb) to obtain transgenic mice allowed to combine the advantages of classical transgenesis and Knock-in strategy (Heintz, 2001). Firstly, the use of large genomic DNA fragments increases the possibility to preserve the key regulatory elements of a gene to allow an accurate expression in vivo. Secondly, BAC constructs insert at random locations throughout the genome and the two loci of the gene of interest are then more likely to be preserved as compare to a knock-in approach. Thirdly, since the site of insertion of the transgene could maintain only part of the native expression profile of the targeted gene, it is possible to select transgenic lines that target specific cell subpopulations or selected brain nuclei.

To target the neuronal population of the striatum the two main transgenes used were fluorescent proteins (GFP or d Tomato) and Cre recombinase (Valjent et al., 2009; see Table 1 for the different cell-type targeting tools). It is worth to mention that the fluorescent proteins are mainly used to target neuronal populations in adult mice to characterize them. Thus it is important that the regulatory sequence used in the BAC mimics the adult in vivo expression in the transgenic mice. In contrast, for Cre recombinase expression, transgenic mice are made for mating with floxed mice, and the resulting mice recapitulate the complete developmental profile (before and after birth) of the targeted gene that could be different from adult expression profile only.

\section{MEDIUM SPINY NEURON TARGETING $B A C-E G F P$ for $D_{1} R$ - and $D_{2} R-M S N$ visualization}

In 2003, the GENSAT project published transgenic BAC reporter mouse lines in which the enhanced green fluorescent protein (EGFP) gene is selectively expressed in a large variety of central nervous system cell-types including the $\mathrm{D}_{1} \mathrm{R}$ or $\mathrm{D}_{2} \mathrm{R}$ expressing cells ( $d r d 1 a$-EGFP and $d r d 2$-EGFP; Gong et al., 2003). Extensive characterization of $d r d 1 a$-EGFP and $d r d 2$-EGFP lines (BertranGonzalez et al., 2008; Matamales et al., 2009) revealed that EGFP expression patterns correlate with previous in situ hybridization or immunohistochemical studies (Hersch et al., 1995; Le Moine and Bloch, 1995) showing that $\mathrm{D}_{1} \mathrm{R}$ and $\mathrm{D}_{2} \mathrm{R}$ are expressed in distinct striatal neuronal populations. In the $d r d 1 a$-EGFP strain, fluorescence was restricted to the striatonigral neuron population while both striatopallidal MSNs and cholinergic interneurons were EGFP-positive in the drd2-EGFP mice (Bertran-Gonzalez et al., 2008). Other reporter BAC strains were also generated to target the striatonigral neurons as chrm4-EGFP line (Gong et al., 2003) and the red fluorophore strain drd1a-tdTomato (Shuen et al., 2008).

These reporter mice represent a powerful tool for identifying each MSN-subtype in multiple experimental paradigms using fixed tissue preparations, fluorescence-activated cell sorting (FACS) or ex vivo electrophysiological recordings (Day et al., 2006, 2008; Lee et al., 2006; Lobo et al., 2006; Wang et al., 2006; Kreitzer and Malenka, 2007; Shen et al., 2007, 2008; BertranGonzalez et al., 2008; Gertler et al., 2008; Matamales et al., 2009; Tecuapetla et al., 2009; Grueter et al., 2010). For instance, they allowed to show that DA depletion induces a loss of spines and glutamatergic synapses selectively on striatopallidal neurons (Day et al., 2006) and that striatopallidal neurons selectively express 
Table 1 | Distinct strategies to target the subpopulations of the striatum.

\begin{tabular}{|c|c|c|c|}
\hline & $\begin{array}{l}\text { Classical transgenesis } \\
\text { or knock-in }\end{array}$ & BAC & Other \\
\hline $\mathrm{D}_{1} \mathrm{R}$ striatonigral neurons & $\begin{array}{l}\text { NSE-tTA (Chen et al., 1998) } \\
\text { drd1a-tox176 (Drago et al., 1998) } \\
\text { drd1a-Cre (Heusner et al., 2008) }\end{array}$ & $\begin{array}{l}\text { drd1a-EGFP, Chrm4-EGFP (Gong et al., 2003) } \\
\text { drd1a-tdTomato (Shuen et al., 2008) } \\
\text { drd1a-Cre (YAC) (Mantamadiotis et al., 2002) } \\
\text { drd1a-Cre (EY262 line) (Gong et al., 2007) } \\
\text { drd1a-DARPP-32/Flag (Bateup et al., 2008) } \\
\text { drd1a-EGFP-L10A (Heiman et al., 2008) } \\
\text { drd1a-iRNA (mGluR5 knock-down) (Novak } \\
\text { et al., 2010) }\end{array}$ & $\begin{array}{l}\text { Volkensin toxin (Harrison et al., 1990) } \\
\text { PPTA-tTA AAV (Hikida et al., 2010) } \\
\text { pDyn-hM } 4 \text { D HSV (Ferguson et al., 2011) }\end{array}$ \\
\hline $\mathrm{D}_{2} \mathrm{R}$ striatopallidal neurons & drd2-hIL-2R $\alpha$ (Sano et al., 2003) & $\begin{array}{l}\text { drd2-EGFP (Gong et al., 2003) } \\
\text { drd2-Cre (ER44 line) (Gong et al., 2007) } \\
\text { drd2-DARPP-32/Myc (Bateup et al., 2008) } \\
\text { drd2-EGFP-L10a (Heiman et al., 2008) } \\
\text { adora2a-Cre (Durieux et al., 2009) }\end{array}$ & $\begin{array}{l}\text { OX7-saporin toxin (Roberts et al., 1993) } \\
\text { PPE-tTA AAV (Hikida et al., 2010) } \\
\text { pEnk-hM } 4 \text { D HSV (Ferguson et al., 2011) }\end{array}$ \\
\hline ChAT interneurons & $\begin{array}{l}\text { mGluR2-hIL-2R } \alpha \text { (Kaneko et al., } \\
\text { 2000) }\end{array}$ & $\begin{array}{l}\text { Chat-EGFP (Gong et al., 2003) } \\
\text { Chat-Cre (GM24 and GM60) (Gong et al., } \\
\text { 2007) }\end{array}$ & $\begin{array}{l}\text { AF64A toxin (Mantione et al., 1981) } \\
\text { SP-PE35 toxin (Saka et al., 2002) }\end{array}$ \\
\hline NPY-NO interneurons & $\mathrm{n} / \mathrm{a}$ & $\begin{array}{l}\text { Npy-Cre (DeFalco et al., 2001) } \\
\text { Npy-Tau-Sapphire-GFP (Pinto et al., 2004; } \\
\text { Roseberry et al., 2004) } \\
\text { Npy-hrGFP (van den Pol et al., 2009) } \\
\text { Nos1-EGFP, Npy-Cre (RH26-CRE and } \\
\text { RH28-CRE) (http://www.gensat.org) }\end{array}$ & SP-PE35 toxin (Saka et al., 2002) \\
\hline PV-interneurons & $\begin{array}{l}\text { Pvalb-IRES-Cre (Hippenmeyer } \\
\text { et al., 2005) } \\
\text { Pvalb-2A-Cre (Madisen et al., } \\
\text { 2009) }\end{array}$ & $\begin{array}{l}\text { Pvalb-EGFP (Meyer et al., 2002) } \\
\text { Pvalb-EGFP (Gong et al., 2003) } \\
\text { Pvalb-Cre (Tanahira et al., 2009) }\end{array}$ & $\mathrm{n} / \mathrm{a}$ \\
\hline CR interneurons & $\mathrm{n} / \mathrm{a}$ & $\mathrm{n} / \mathrm{a}$ & $\mathrm{n} / \mathrm{a}$ \\
\hline
\end{tabular}

n/a: not available.

an endocannabinoid-mediated long-term depression (eCB-LTD) that is disrupted in DA-depleted animals (Kreitzer and Malenka, 2007). Specific expression profiles of $D_{1} R$ and $D_{2} R$ MSNs were determined using FACS assays coupled to microarray analysis in $d r d 1 a_{-}$, $d r d 2-$, and chrm4-EGFP mice (Lobo et al., 2006), identifying multiple new genes preferentially expressed in each MSN-subtype.

Recent report pointed out major abnormalities in $d r d 2$-EGFP mice from GENSAT (Kramer et al., 2010). Alvarez and colleagues showed that, as compare to WT mice, $d r d 2$-EGFP mice exhibit a $D_{2} R$ overexpression (i.e., increase in striatal $D_{2} R$ binding and $D_{2} R$ mRNA levels), enhanced electrophysiological responses to $D_{2} R$ activation in midbrain dopaminergic neurons as well as impaired DA clearance after NAc stimulation or cocaine administration (Kramer et al., 2010). Behaviorally, drd2-EGFP mice display hyperactivity in novel environment, hypersensitivity to $\mathrm{D}_{2} \mathrm{R}$-like agonists and deficient acute and chronic response to cocaine (Kramer et al., 2010).

These results highlight the importance of extensive characterization and adequate controls when using transgenic mice in neuroscience research.

\section{Cre BAC for manipulation of striatonigral and striatopallidal neurons or genes to shed light on their physiological roles}

The first attempt to use a large mouse genomic fragment $(140 \mathrm{~kb})$ of drdla gene has been undertaken with a yeast artificial chromosome (YAC) to unravel the role of cAMP responsive element binding protein (CREB) and cAMP responsive element modulatory protein (CREM) in striatal neurodegeneration (Mantamadiotis et al., 2002). The extensive characterization of these mice showed that the transgene has a spatiotemporal expression pattern that closely recapitulated the pattern of $d r d 1 a$ gene but is expressed in most dopaminoceptive neurons of the striatum and not only in the striatonigral neurons (Lemberger et al., 2007).

Having generated a large library of BAC-GFP mice, the GENSAT project then proceeded to generate a BAC-Cre mice library (Gong et al., 2007). In a first study, Greengard and colleagues used the $d r d 1 a-C r e$ (EY262 line) and $d r d 2$-Cre (ER44 line) mice to demonstrate that deletion of the histone methylase GLP/G9a led to de-repression of non-neuronal genes in each MSN populations. The study showed an altered locomotor response to pharmacological agents that target striatonigral and striatopallidal neurons in the conditional KO mice (Schaefer 
et al., 2009). In a second study, they crossed the same lines of $d r d 1 a$-Cre and $d r d 2$-Cre mice with dopamine- and cAMPregulated phosphoprotein $\mathrm{Mr} 32 \mathrm{kDa}$ (DARPP-32) floxed mice. Striatonigral DARPP-32-deleted mice show a decrease in basal and cocaine-induced locomotion and an abolition of L-DOPAinduced dyskinesia. Conversely, striatopallidal DARP32-deleted mice have increased locomotor activity and reduced haloperidolinduced catalepsy (Bateup et al., 2010). In this last study, they clearly showed that the deletions of DARPP-32 in striatonigral or striatopallidal neurons are specific. However, since DARPP32 is only expressed in MSNs, these experiments do not rule out that, $d r d 2$-Cre mice, Cre recombinase is also expressed in cholinergic interneurons and/or DA neurons as shown for $\mathrm{D}_{2}-\mathrm{GFP}$ (Matamales et al., 2009).

In parallel with the GENSAT BAC-Cre, other striatopallidal-Cre mice have been developed by choosing the adora2a gene (adenosine $A_{2 A}$ receptor) which is expressed in striatopallidal neurons but not in other striatal neuronal populations or in the presynaptic DA neurons (Durieux et al., 2009). The characterization of mice resulting from the crossing between adora2a-Cre mice and inducible diphtheria toxin receptor (iDTR) mice (Buch et al., 2005) after striatal diphtheria toxin injection have demonstrated that only striatopallidal neurons were targeted. The resulting mice show an increase in spontaneous locomotor activity after a whole striatum striatopallidal neuron ablation and an increase of amphetamine CPP after ventral striatum striatopallidal neuron ablation, thus demonstrating the in vivo roles of striatopallidal neurons in both locomotion and drug reinforcement inhibition (Durieux et al., 2009).

The most recent advances in this domain have been obtained by combining BAC-Cre expressing mice with optogenetics, allowing control of neuron-type activity with high temporal and spatial resolutions (Kravitz et al., 2010; Lobo et al., 2010). In this paradigm, two types of membrane light-sensitive proteins are used to respectively activate or silence neurons: the channelrhodopsin-2 (ChR2) cation channel and the halorhodopsin (NpHR) chloride pump respectively (Boyden et al., 2005; Zhang et al., 2007). Blue light induces a conformational change that opens ChR2 pore which rapidly and reversibly depolarizes the cell membrane and triggers action potentials (Boyden et al., 2005), while yellow light activates $\mathrm{NpHR}$, which generates a chloride flow and causes rapid and reversible cell membrane hyperpolarization that prevents action potentials (Zhang et al., 2007).

Stereotactic injections of Cre-dependent ChR2 or NpHR adeno associated virus (AAV) in Cre lines lead to cell-type specific expressions of the light-sensitive proteins and optical stimulation is applied locally, through an optical fiber coupled to a diode laser, inserted in the brain area of interest (Sohal et al., 2009; Carter et al., 2010).

A first study using striatal BAC-Cre strains has demonstrated that bilateral excitation of dorsomedial striatal neurons of $d r d 1 a$-Cre mice injected with AAV-DIO-ChR2-YFP (in which Cre-dependent expression of ChR2 is coupled to the yellow fluorescent protein, YFP) causes reduced freezing and increased locomotion (Kravitz et al., 2010). The same dorsomedial neuron excitation of $d r d 2$-Cre mice injected with AAV-DIO-ChR2-YFP increases freezing, and bradykinesia, and decreases locomotor initiation. In a mouse model of Parkinson's disease (injection of 6-hydroxydopamine in dorsomedial striatum), dorsomedial excitation of striatonigral neurons rescued these deficits (Kravitz et al., 2010). They showed that the AAV recombined mainly in striatonigral and striatopallidal neurons, respectively, by demonstrating the presence of YFP staining in the targets nuclei of the two neuronal populations ( $\mathrm{SNr}$ and GP, respectively). However, they did not specify which drd1a-Cre (EY217, EY242, EY262, EY266, FK150, and FK164) and $d r d 2$-Cre (ER43 and ER44) GENSAT lines were used and this could be of importance because the Cre expression profiles are different in these lines. Yet, some striatal PV and NPY interneurons are also targeted in $d r d 1 a$-Cre and ChAT interneurons are targeted in $d r d 2$-Cre mice (Kravitz et al., 2010). Finally, DA neurons are not targeted in $d r d 2$-Cre mice by these stereotaxic injections of AAV-DIO-ChR2-YFP in the dorsomedial striatum.

The second optogenetic study using also the $d r d 1 a$-Cre and $d r d 2$-Cre GENSAT mice and AAV-DIO-ChR2-YFP, targets the NAc to unravel the role of direct and indirect pathways (Lobo et al., 2010). Illumination of NAc neurons in $d r d 2$-Cre mice injected with AAV-DIO-ChR2-YFP suppresses cocaine reward whereas the opposite effect is found by illumination of the neurons in the NAc of $d r d 1 a-C r e$ mice injected with AAV-DIO-ChR2-YFP (Lobo et al., 2010). These results mimic those obtained in Trkb (the brainderived neurotrophic factor receptor) floxed mice with the same $d r d 2$-Cre and drd1a-Cre mice (Lobo et al., 2010).

It is important to conclude by noting that currently GENSAT offers six different $d r d 1 a$-Cre lines and two $d r d 2$-Cre lines ${ }^{1}$ with variable Cre recombinase expression profile that potentially allow to target different populations and subregions in the striatum. It is worth also to note that the Cre recombinase expression in the BAC-Cre mice is generally evaluated by crossing them with reporter strains as Rosa26 Lox-Stop-Lox EGFP; meaning that only the spatiotemporal profile of the Cre recombinase can be deduced and not its the level of expression.

\section{Others transgene-BAC}

$d r d 1 a$ and $d r d 2$ BAC have been used to express other transgenes than eGFP and Cre recombinase. Indeed, to unravel the specific role of DARPP-32 in striatonigral and striatopallidal neurons Greengard and colleagues have generated two different BAC transgenic mice: one containing a bicistronic transgene composed of a C-terminal Flag-tagged DARPP-32 and a Venus fluorescent protein under the control of the drdla promoter on a BAC and the other containing the bicistronic transgene composed of a C-terminal Myc-tagged DARPP-32 and enhanced cyan fluorescent protein (Bateup et al., 2008). Characterization of these two transgenic mice show that $36.7 \%$ of striatal cells expressed GFP mRNA in $d r d 1 a$-DARPP-32/Flag mice and $41.4 \%$ in $d r d 2$ DARPP-32/Myc mice and that the expression is specific to striatonigral or striatopallidal neurons, respectively (Bateup et al., 2008). These transgenic mice have allowed to demonstrate that cocaine increases T-34 phosphorylation of DARPP-32 specifically in striatonigral neurons whereas haloperidol induces the

${ }^{1}$ http://www.gensat.org/cre.jsp 
same type of phosphorylation selectively in striatopallidal neurons (Bateup et al., 2008).

Greengard, Heintz, and colleagues have also generated two other mouse lines with $d r d 1 a$ or $d r d 2$ BAC that allow to purify polysomal mRNAs of specific neuronal populations to identify molecular changes in normal condition or after cocaine injection (Heiman et al., 2008). With this purpose, a fusion of EGFP to the $\mathrm{N}$ terminal of the large subunit ribosomal protein L10a was inserted under the control of the promoter of either $d r d 1 a$ or $d r d 2$ in an appropriate BAC. The $d r d 1 a$-EGFP-L10a line (CP73) showed expression of EGFP in the dorsal and ventral striatum, olfactory bulb, olfactory tubercle, and cortical layers five and six. The drd2-EGFP-L10a line (CP101) showed expression of EGFP in the dorsal and ventral striatum, olfactory tubercle, and hippocampus, as well as in the substantia nigra pars compacta and ventral tegmental area. Enkephalin immunostaining in the striatum colocalized with EGFP in $d r d 2$-EGFP-L10a mice but not in drd1a-EGFP-L10a. Polysomal mRNAs of isolated and homogenized striata were immunoprecipitated with magnetic beads coated with an antibody against EGFP on each of this two lines and translational profiling was determined by microarrays. Around 70 additional striatopallidal-enriched transcripts and more than 150 additional striatonigral-enriched transcripts with respect to the FACS-isolated MSN study (Lobo et al., 2006) were identified by this method (Heiman et al., 2008). The same analysis was performed after acute or chronic cocaine injection and hundreds of genes whose expression was increased or decreased in each cell-type were identified (Heiman et al., 2008).

Another study has used a $d r d 1 a$ BAC to express a short hairpin RNA to knock-down mGluR5 (Novak et al., 2010). GFP was introduced in tandem with two microRNAs against mGluR5 to track the expression of the sh-RNA. The GFP was expressed in 53\% of striatal neurons that correspond to DARPP-32 neurons that do not express enkephalin, thus striatonigral neurons as expected (Novak et al., 2010). Moreover, the mRNA level of mGluR5 decreases significantly only in the striatum. These transgenic mice show impairment in the reinstatement of cocaine-seeking induced by a cocaine-paired stimulus due to a deficit in specific incentive learning processes (Novak et al., 2010).

\section{TARGETING OF STRIATAL INTERNEURONS}

GENSAT project generated choline acetyltransferase (ChAT)EGFP (Gong et al., 2003) and ChAT-Cre (Gong et al., 2007) mice. Two Chat BAC-Cre transgenic lines (GM24 and GM60) showed brain Cre recombination that matched the expression of Chat in the adult, while the GM53 founder exhibited Cre recombination only in brainstem and spinal cord motor neurons (see text footnote 1). The GM24 strain was recently used in an optogenetic paradigm showing that ChAT interneurons in the NAc could be activated by cocaine and that silencing this drug-induced activity during cocaine exposure disrupted cocaine place preference conditioning (Witten et al., 2010).

Enhanced green fluorescent protein expression in parvalbumin (PV) interneurons of the striatum was initially obtained in a BAC line (Pvalb-EGFP; Meyer et al., 2002) with $96 \%$ of colocalization, calculated as the number of EGFP-positive cells stained with PV antibody. Using these Pvalb-EGFP mice, Freiman et al. (2006) found that activation of $\mathrm{CB} 1$ cannabinoid receptors led to presynaptic inhibition of PV-interneurons to MSN neurotransmission. Pvalb-EGFP mice were also developed by the GENSAT project (Gong et al., 2003) in which EGFP detection in the striatum seems to match the endogenous pattern of Pvalb expression but was not extensively characterized.

A Pvalb-Cre BAC strain, with a Cre recombinase DNA inserted into the Pvalb start codon, was generated by Tanahira et al. (2009), in which the Cre expression seems to match the PV expression in basal ganglia, including the caudate nucleus and the putamen (determined by Cre and PV double immunohistochemistry).

$N p y$-Cre BAC mice were generated by Friedman and colleagues at the Rockefeller University (DeFalco et al., 2001) to trace hypothalamic NPY neuron connections after stereotactic injection of a Cre-dependent GFP virus. Extensive characterization of Cre expression with a reporter strain was not performed in these mice and, notably, presence of Cre recombinase in the striatum remains elusive. Recently, the GENSAT project generated Npy-Cre mice (founders RH26-CRE and RH28-CRE) exhibiting a Cre expression pattern spatially similar to NPY (see text footnote 1) but Cre and NPY colocalization needs to be performed in these mice.

Friedman's laboratory also developed $N p y$-Tau-Sapphire-GFP BAC mice to investigate functions of NPY-positive neurons in the arcuate nucleus of the hypothalamus (Pinto et al., 2004; Roseberry et al., 2004). Unfortunately, the GFP expression in these mice appeared lower than revealed by histochemistry (van den Pol et al., 2009), and recent study showed morphological and electrophysiological pathological abnormalities in $N p y$-Tau-Sapphire-GFP interneurons compared with WT NPY interneurons that could be due to the overexpression of tau-coupled reporter constructs (Rancillac et al., 2010). Another group generated a BAC Npyhuman codon corrected Renilla (hr)-GFP transgenic mice, with a GFP from a type of soft coral (sea pansy Renilla) that seems to be more stable and brighter than other green fluorescent protein (van den Pol et al., 2009). In these Npy-hrGFP mice, the caudateputamen and the NAc contained scattered intensely GFP-positive cells (van den Pol et al., 2009) and colocalization of NPY and GFP in the striatum was confirmed by Partridge et al. (2009) that used these mice to specify properties of synaptic connections onto striatal NPY interneurons.

Finally, the GENSAT project also generated BAC lines in which GFP is under control of the neuronal nitric oxide synthase (nNOS) promoter $(\text { Nos } 1)^{2}$. However, none of the Nos1-EGFP lines generated show EGFP in striatal nNOS interneurons.

To date, to the best of our knowledge, no genetic tool has been developed to target selectively the striatal calretinin-positive interneurons.

\section{VIRAL TARGETING}

Recently, two papers have targeted striatonigral and striatopallidal neurons in mice and rats by using viral vectors (Hikida et al., 2010; Ferguson et al., 2011). To target mice striatonigral neurons, the -1525 to +543 residues of the mouse PPTA gene (Substance P) have been inserted in front of Flag-tagged tTA in

\footnotetext{
${ }^{2}$ http://www.gensat.org
} 
an AAV vector whereas the -1834 to +148 residues of the mouse Penk gene (Enkephalin) have been used to target the striatopallidal neurons (Hikida et al., 2010). The AAVs have been injected in transgenic mice (TN) containing the TRE-GFP-tetanus toxin transgene allowing that cause the inhibition of neurotransmission in neurons expressing tTA when doxycycline is withdrawn. The TN mice bilaterally injected into 11 sites of the striatum with AAVPPTA-tTA showed an exclusive GFP immunostaining in $74.2 \%$ of SP-positive cells whereas in TN mice injected with AAV-PPE-tTA $71.1 \%$ of ENK-containing neurons were immunostained by GFP, demonstrating a specific targeting of striatonigral and striatopallidal neurons, respectively (Hikida et al., 2010). Surprisingly, despite these percentage of targeted neurons targeted in either direct or indirect pathways whose neurotransmission was abolished, the resulting mice did not show a decrease or increase of spontaneous locomotor activity (Hikida et al., 2010) in contrast to the results obtained with BAC (Durieux et al., 2009; Bateup et al., 2010; Kravitz et al., 2010). TN mice bilaterally injected into four sites of the NAc with the transgenic AAV that results in the blockade of the direct pathway showed a decrease in cocaine-induced CPP (Hikida et al., 2010) in accordance with the results obtained in BAC mice using optogenetic approaches (Lobo et al., 2010). No difference in cocaine-induced CCP was found when the indirect pathway was inhibited (Hikida et al., 2010) in contrast with the results obtained with BAC technology (Durieux et al., 2009; Lobo et al., 2010). These differences could be explained by the different proportion of neurons that were targeted by the two approaches.

In rats, the availability of transgenic tools is much more limited than in mice. A very recent study reports the genetic targeting of both MSN populations. The -2609 to +52 residues of the rat Penk gene (Enkephalin) and the -1858 to +135 residues of the rat $P d y n$ gene (Dynorphin) were inserted in herpes simplex virus (HSV) in front of an hemagglutinin-tagged engineered GPCR (derived from the $\mathrm{G}_{\mathrm{i} / \mathrm{o}}$-coupled human muscarinic $\mathrm{M}_{4}, \mathrm{hM}_{4} \mathrm{D}$, activated by an inert ligand, CNO; Ferguson et al., 2011). Administration of $\mathrm{CNO}$ induced the activation of Kir3 channel in neurons expressing

\section{REFERENCES}

Bateup, H. S., Santini, E., Shen, W., Birnbaum, S., Valjent, E., Surmeier, D. J., Fisone, G., Nestler, E. J., and Greengard, P. (2010). Distinct subclasses of medium spiny neurons differentially regulate striatal motor behaviors. Proc. Natl. Acad. Sci. U.S.A. 107, 14845-14850.

Bateup, H. S., Svenningsson, P., Kuroiwa, M., Gong, S., Nishi, A., Heintz, N., and Greengard, P. (2008). Cell type-specific regulation of DARPP-32 phosphorylation by psychostimulant and antipsychotic drugs. Nat. Neurosci. 11, 932-939.

Bertran-Gonzalez, J., Bosch, C., Maroteaux, M., Matamales, M., Hervé, D., Valjent, E., and Girault, J. (2008). Opposing patterns of signaling activation in dopamine D1 and D2 receptor-expressing striatal neurons in response to cocaine and haloperidol. J. Neurosci. 28, 5671-5685.

Beutler, L. R., Wanat, M. J., Quintana, A., Sanz, E., Bamford, N. S., Zweifel, L. S., and Palmiter, R. D. (2011). Balanced NMDA receptor activity in dopamine D1 receptor (D1R)- and $\mathrm{D} 2 \mathrm{R}$-expressing medium spiny neurons is required for amphetamine sensitization. Proc. Natl. Acad. Sci. U.S.A. 108, 4206-4211.

Bolam, J., Hanley, J., and Booth, P. (2000). Synaptic organisation of the basal ganglia. J. Anat. 196, 527-542.

Book, A. A., Wiley, R. G., and Schweitzer, J. B. (1992). Specificity of 192 IgGsaporin for NGF receptor-positive cholinergic basal forebrain neurons in the rat. Brain Res. 590, 350-355.

Boyden, E. S., Zhang, F., Bamberg, E., Nagel, G., and Deisseroth, K. (2005). Millisecond-timescale,

$\mathrm{hM}_{4} \mathrm{D}$, resulting in membrane hyperpolarization, and transient neuronal silencing. In rats infused into one site of the dorsal striatum with pEnk-hM ${ }_{4} \mathrm{D}$ HSV, $90 \%$ of hemagglutinin cells were Enk-positive and 6\% were SP-positive whereas with pDyn-hM $\mathrm{M}_{4} \mathrm{D}$ HSV $95 \%$ of hemagglutinin cells were substance $P$ positive and $5 \%$ were Enk-positive (Ferguson et al., 2011). The percentage of Enkor SP- positive neurons infected in the dorsal striatum by these HSV vectors was unknown. CNO treatment decreased the number of evoked action potentials in $\mathrm{hM}_{4} \mathrm{D}$-expressing neurons. In pEnk- $\mathrm{hM}_{4} \mathrm{D}$ rats, $\mathrm{CNO}$ treatment facilitated the development of a robust amphetamine sensitization in contrast with $\mathrm{pDyn}-\mathrm{hM}_{4} \mathrm{D}$ rats (Ferguson et al., 2011).

\section{CONCLUSION AND PERSPECTIVES}

The recent advances in genetic targeting have allowed to address a lot of important physiological issues in the striatum which were unattainable in the past. However each of these approaches (Knock-in, BAC, Virus...) needs an extensive characterization of the resulting transgenic mice to avoid some overstated conclusions. The optogenetics by its flexibility and its time resolution will certainly allow to solve new important questions in striatal physiology. Moreover, a very recent advance in optogenetic tools (Ye et al., 2011) has demonstrated the possibility to control transcription of specific transgenes by light. This additional progress will allow not only to control the activity of a neuronal population but also to control the expression of a specific gene in this neuronal population. A next important step will be to export all these tools to other models than mouse, as rat and monkey, where more elaborated behavioral paradigms are possible.

\section{ACKNOWLEDGMENTS}

Pierre F. Durieux is Research Fellow of the FRS-FNRS (chargé de recherche FNRS) and AdKdE Research Associate of the FRS-FNRS (Belgium). This study was supported by FMRE (Belgium), FRSFNRS (Belgium), FER from ULB, Action de Recherche Concertée from the CFWB.

genetically targeted optical control of neural activity. Nat. Neurosci. 8, 1263-1268.

Buch, T., Heppner, F. L., Tertilt, C., Heinen, T. J. A. J., Kremer, M., Wunderlich, F. T., Jung, S., and Waisman, A. (2005). A Cre-inducible diphtheria toxin receptor mediates cell lineage ablation after toxin administration. Nat. Methods 2, 419-426.

Carter, M. E., Yizhar, O., Chikahisa, S., Nguyen, H., Adamantidis, A., Nishino, S., Deisseroth, K., and de Lecea, L. (2010). Tuning arousal with optogenetic modulation of locus coeruleus neurons. Nat. Neurosci. 13 , 1526-1533.

Casanova, E., Fehsenfeld, S., Mantamadiotis, T., Lemberger, T., Greiner, E., Stewart, A. F., and Schütz, G. (2001). A CamKIIalpha iCre BAC allows brain-specific gene inactivation. Genesis 31, 37-42.
Chen, J., Kelz, M. B., Zeng, G., Sakai, N., Steffen, C., Shockett, P. E., Picciotto, M. R., Duman, R. S., and Nestler, E. J. (1998). Transgenic animals with inducible, targeted gene expression in brain. Mol. Pharmacol. 54, 495-503.

Colby, C. R., Whisler, K., Steffen, C., Nestler, E. J., and Self, D. W. (2003) Striatal cell type-specific overexpression of DeltaFosB enhances incentive for cocaine. J. Neurosci. 23, 2488-2493.

Day, M., Wang, Z., Ding, J., An, X., Ingham, C. A., Shering, A. F., Wokosin, D., Ilijic, E., Sun, Z., Sampson, A. R., Mugnaini, E., Deutch, A. Y., Sesack, S. R., Arbuthnott, G. W., and Surmeier, D. J. (2006). Selective elimination of glutamatergic synapses on striatopallidal neurons in Parkinson disease models. Nat. Neurosci. 9, 251-259. 
Day, M., Wokosin, D., Plotkin, J. L., Tian, X., and Surmeier, D. J. (2008). Differential excitability and modulation of striatal medium spiny neuron dendrites. J. Neurosci. 28, 11603-11614.

DeFalco, J., Tomishima, M., Liu, H., Zhao, C., Cai, X., Marth, J. D., Enquist, L., and Friedman, J. M. (2001). Virus-assisted mapping of neural inputs to a feeding center in the hypothalamus. Science 291, 2608-2613.

Drago, J., Padungchaichot, P., Wong, J. Y., Lawrence, A. J., McManus, J. F., Sumarsono, S. H., Natoli, A. L., Lakso, M., Wreford, N., Westphal, H., Kola, I., and Finkelstein, D. I. (1998). Targeted expression of a toxin gene to D1 dopamine receptor neurons by cre-mediated site-specific recombination. J. Neurosci. 18, 9845-9857.

Durieux, P. F., Bearzatto, B., Guiducci, S., Buch, T., Waisman, A., Zoli, M., Schiffmann, S. N., and de Kerchove d'Exaerde, A. (2009). D2R striatopallidal neurons inhibit both locomotor and drug reward processes. Nat. Neurosci. 12, 393-395.

Ferguson, S. M., Eskenazi, D., Ishikawa, M., Wanat, M. J., Phillips, P. E. M., Dong, Y., Roth, B. L., and Neumaier, J. F. (2011). Transient neuronal inhibition reveals opposing roles of indirect and direct pathways in sensitization. Nat. Neurosci. 14, 22-24.

Freiman, I., Anton, A., Monyer, H., Urbanski, M. J., and Szabo, B. (2006). Analysis of the effects of cannabinoids on identified synaptic connections in the caudate-putamen by paired recordings in transgenic mice. J. Physiol. 575, 789-806.

Gantois, I., Fang, K., Jiang, L., Babovic, D., Lawrence, A. J., Ferreri, V., Teper, Y., Jupp, B., Ziebell, J., MorgantiKossmann, C. M., O’Brien, T. J., Nally, R., Schütz, G., Waddington, J., Egan, G. F., and Drago, J. (2007). Ablation of D1 dopamine receptorexpressing cells generates mice with seizures, dystonia, hyperactivity, and impaired oral behavior. Proc. Natl. Acad. Sci. U.S.A. 104, 4182-4187.

Gerfen, C. R., Engber, T. M., Mahan, L. C., Susel, Z., Chase, T. N., Monsma, F. J. Jr., and Sibley, D. R. (1990). D1 and D2 dopamine receptorregulated gene expression of striatonigral and striatopallidal neurons. Science 250, 1429-1432.

Gertler, T. S., Chan, C. S., and Surmeier, D. J. (2008). Dichotomous anatomical properties of adult striatal medium spiny neurons. J. Neurosci. 28, 10814-10824.

Gong, S., Doughty, M., Harbaugh, C. R., Cummins, A., Hatten, M. E., Heintz, N., and Gerfen, C. R. (2007).
Targeting Cre recombinase to specific neuron populations with bacterial artificial chromosome constructs. J. Neurosci. 27, 9817-9823.

Gong, S., Zheng, C., Doughty, M. L., Losos, K., Didkovsky, N., Schambra, U. B., Nowak, N. J., Joyner, A., Leblanc, G., Hatten, M. E., and Heintz, N. (2003). A gene expression atlas of the central nervous system based on bacterial artificial chromosomes. Nature 425, 917-925.

Gossen, M., and Bujard, H. (2002). Studying gene function in eukaryotes by conditional gene inactivation. Annu. Rev. Genet. 36, 153-173.

Graybiel, A. (1990). Neurotransmitters and neuromodulators in the basal ganglia. Trends Neurosci. 13, 244-254.

Graybiel, A. M. (2008). Habits, rituals, and the evaluative brain. Annu. Rev. Neurosci. 31, 359-387.

Groenewegen, H. (2003). The basal ganglia and motor control. Neural Plast. 10, 107-120.

Grueter, B. A., Brasnjo, G., and Malenka, R. C. (2010). Postsynaptic TRPV1 triggers cell type-specific long-term depression in the nucleus accumbens. Nat. Neurosci. 13, 1519-1525.

Harrison, M. B., Wiley, R. G., and Wooten, G. F. (1990). Selective localization of striatal D1 receptors to striatonigral neurons. Brain Res. 528, 317-322.

Heiman, M., Schaefer, A., Gong, S., Peterson, J. D., Day, M., Ramsey, K. E., Suarez-Farinas, M., Schwarz, C., Stephan, D. A., Surmeier, J. D., Greengard, P., and Heintz, N. (2008). A translational profiling approach for the molecular characterization of CNS cell types. Cell 135, 738-748.

Heintz, N. (2001). BAC to the future: the use of bac transgenic mice for neuroscience research. Nat. Rev. Neurosci. 2, 861-870.

Hersch, S., Ciliax, B., and Gutekunst, C. (1995). Electron microscopic analysis of D1 and D2 dopamine receptor proteins in the dorsal striatum and their synaptic relationships with motor corticostriatal afferents. J. Neurosci. 15, 5222-5237.

Hervé, D., Lévi-Strauss, M., MareySemper, I., Verney, C., Tassin, J. P., Glowinski, J., and Girault, J. A. (1993). G(olf) and Gs in rat basal ganglia: possible involvement of $\mathrm{G}$ (olf) in the coupling of dopamine D1 receptor with adenylyl cyclase. $J$. Neurosci. 13, 2237-2248.

Heusner, C. L., Beutler, L. R., Houser, C. R., and Palmiter, R. D. (2008). Deletion of GAD67 in dopamine receptor-1 expressing cells causes specific motor deficits. Genesis 46, 357-367.
Hikida, T., Kaneko, S., Isobe, T., Kitabatake, Y., Watanabe, D., Pastan, I., and Nakanishi, S. (2001). Increased sensitivity to cocaine by cholinergic cell ablation in nucleus accumbens. Proc. Natl. Acad. Sci. U.S.A. 98, 13351-13354

Hikida, T., Kimura, K., Wada, N., Funabiki, K., and Nakanishi, S. (2010). Distinct roles of synaptic transmission in direct and indirect striatal pathways to reward and aversive behavior. Neuron 66, 896-907.

Hippenmeyer, S., Vrieseling, E., Sigrist, M., Portmann, T., Laengle, C., Ladle, D. R., and Arber, S. (2005). A developmental switch in the response of DRG neurons to ETS transcription factor signaling. PLoS Biol. 3, e159. doi: 10.1371/journal.pbio.0030159

Huang, Y., Simpson, E., Kellendonk, C., and Kandel, E. R. (2004). Genetic evidence for the bidirectional modulation of synaptic plasticity in the prefrontal cortex by D1 receptors. Proc. Natl. Acad. Sci. U.S.A. 101, 3236-3241.

Kaneko, S., Hikida, T., Watanabe, D. Ichinose, H., Nagatsu, T., Kreitman, R. J., Pastan, I., and Nakanishi, S. (2000). Synaptic integration mediated by striatal cholinergic interneurons in basal ganglia function. Science 289, 633-637.

Kawaguchi, Y., Wilson, C. J., Augood, S. J., and Emson, P. C. (1995). Striatal interneurones: chemical, physiological and morphological characterization. Trends Neurosci. 18, 527-535.

Kelly, M. A., Rubinstein, M., Phillips, T. J., Lessov, C. N., Burkhart-Kasch, S., Zhang, G., Bunzow, J. R., Fang, Y., Gerhardt, G. A., Grandy, D. K., and Low, M. J. (1998). Locomotor activity in D2 dopamine receptordeficient mice is determined by gene dosage, genetic background, and developmental adaptations. J. Neurosci. 18, 3470-3479.

Kelz, M. B., Chen, J., Carlezon, W. A., Whisler, K., Gilden, L., Beckmann, A. M., Steffen, C., Zhang, Y. J., Marotti, L., Self, D. W., Tkatch, T., Baranauskas, G., Surmeier, D. J., Neve, R. L., Duman, R. S., Picciotto, M. R., and Nestler, E. J. (1999). Expression of the transcription factor deltaFosB in the brain controls sensitivity to cocaine. Nature 401, 272-276.

Kitabatake, Y., Hikida, T., Watanabe, D., Pastan, I., and Nakanishi, S. (2003). Impairment of reward-related learning by cholinergic cell ablation in the striatum. Proc. Natl. Acad. Sci. U.S.A. 100, 7965-7970.

Kramer, P. F., Christensen, C. H., Hazelwood, L. A., Dobi, A., Bock, R., Sibley, D. R., Mateo, Y., and Alvarez, V. A. (2010). Dopamine D2 receptor overexpression alters behavior and physiology in Drd2-EGFP mice. J. Neurosci. 31, 126-132.

Kravitz, A. V., Freeze, B. S., Parker, P. R. L., Kay, K., Thwin, M. T., Deisseroth, K., and Kreitzer, A. C. (2010). Regulation of parkinsonian motor behaviours by optogenetic control of basal ganglia circuitry. Nature 466, 622-626.

Kreitzer, A. C., and Malenka, R. C. (2007). Endocannabinoid-mediated rescue of striatal LTD and motor deficits in Parkinson's disease models. Nature 445, 643-647.

Kreitzer, A. C., and Malenka, R. C. (2008). Striatal plasticity and basal ganglia circuit function. Neuron 60, 543-554.

Le Moine, C., and Bloch, B. (1995). D1 and D2 dopamine receptor gene expression in the rat striatum: sensitive cRNA probes demonstrate prominent segregation of D1 and D2 mRNAs in distinct neuronal populations of the dorsal and ventral striatum. J. Comp. Neurol. 355, 418-426.

Leanza, G., Nilsson, O. G., Wiley, R. G., and Björklund, A. (1995). Selective lesioning of the basal forebrain cholinergic system by intraventricular 192 IgG-saporin: behavioural, biochemical and stereological studies in the rat. Eur. J. Neurosci. 7, 329-343.

Lee, K., Kim, Y., Kim, A. M., Helmin, K., Nairn, A. C., and Greengard, P. (2006). Cocaine-induced dendritic spine formation in D1 and D2 dopamine receptor-containing medium spiny neurons in nucleus accumbens. Proc. Natl. Acad. Sci. U.S.A. 103, 3399-3404.

Lemberger, T., Parlato, R., Dassesse, D. Westphal, M., Casanova, E., Turiault, M., Tronche, F., Schiffmann, S. N., and Schütz, G. (2007). Expression of Cre recombinase in dopaminoceptive neurons. BMC Neurosci. 8, 4 . doi: 10.1186/1471-2202-8-4

Lobo, M. K., Covington, H. E., Chaudhury, D., Friedman, A. K., Sun, H., Damez-Werno, D., Dietz, D. M. Zaman, S., Koo, J. W., Kennedy, P. J., Mouzon, E., Mogri, M., Neve, R. L., Deisseroth, K., Han, M. H., and Nestler, E. J. (2010). Cell type-specific loss of BDNF signaling mimics optogenetic control of cocaine reward. Science 330, 385-390.

Lobo, M. K., Karsten, S. L., Gray, M., Geschwind, D. H., and Yang, X. W. (2006). FACS-array profiling of striatal projection neuron subtypes in juvenile and adult mouse brains. Nat. Neurosci. 9, 443-452.

Madisen, L., Zwingman, T. A., Sunkin, S. M., Oh, S. W., Zariwala, H. A., 
Gu, H., Ng, L. L., Palmiter, R. D., Hawrylycz, M. J., Jones, A. R., Lein, E. S., and Zeng, H. (2009). A robust and high-throughput Cre reporting and characterization system for the whole mouse brain. Nat. Neurosci. $13,133-140$.

Mantamadiotis, T., Lemberger, T., Bleckmann, S. C., Kern, H., Kretz, O., Villalba, A. M., Tronche, F., Kellendonk, C., Gau, D., Kapfhammer, J., Otto, C., Schmid, W., and Schütz, G. (2002). Disruption of CREB function in brain leads to neurodegeneration. Nat. Genet. 31, 47-54.

Mantione, C. R., Fisher, A., and Hanin, I. (1981). The AF64a-treated mouse: possible model for central cholinergic hypofunction. Science 213, 579-580.

Matamales, M., Bertran-Gonzalez, J., Salomon, L., Degos, B., Deniau, J., Valjent, E., Hervé, D., and Girault, J. (2009). Striatal medium-sized spiny neurons: identification by nuclear staining and study of neuronal subpopulations in BAC transgenic mice. PLoS ONE 4, e4770. doi: 10.1371/journal.pone.0004770

Meyer, A. H., Katona, I., Blatow, M., Rozov, A., and Monyer, H. (2002). In vivo labeling of parvalbuminpositive interneurons and analysis of electrical coupling in identified neurons. J. Neurosci. 22, 7055-7064.

Nestler, E. J. (2005). Is there a common molecular pathway for addiction? Nat. Neurosci. 8, 1445-1449.

Novak, M., Halbout, B., O'Connor, E. C., Rodriguez Parkitna, J., Su, T., Chai, M., Crombag, H. S., Bilbao, A., Spanagel, R., Stephens, D. N., Schütz, G., and Engblom, D. (2010). Incentive learning underlying cocaineseeking requires mGluR5 receptors located on dopamine D1 receptorexpressing neurons. J. Neurosci. 30, 11973-11982.

Partridge, J. G., Janssen, M. J., Chou, D. Y. T., Abe, K., Zukowska, Z., and Vicini, S. (2009). Excitatory and inhibitory synapses in neuropeptide Y-expressing striatal interneurons. J. Neurophysiol. 102, 3038-3045.

Pinto, S., Roseberry, A. G., Liu, H., Diano, S., Shanabrough, M., Cai, X., Friedman, J. M., and Horvath, T. L. (2004). Rapid rewiring of arcuate nucleus feeding circuits by leptin. Science 304, 110-115.

Ralph-Williams, R. J., LehmannMasten, V., Otero-Corchon, V., Low, M. J., and Geyer, M. A. (2002). Differential effects of direct and indirect dopamine agonists on prepulse inhibition: a study in D1 and D2 receptor knock-out mice. J. Neurosci. 22, 9604-9611.
Rancillac, A., Lainé, J., Perrenoud, Q., Geoffroy, H., Ferezou, I., Vitalis, T., and Rossier, J. (2010). Degenerative abnormalities in transgenic neocortical neuropeptide $\mathrm{Y}$ interneurons expressing tau-green fluorescent protein. J. Neurosci. Res. 88, 487-499.

Robbins, T. W., and Everitt, B. J. (1996). Neurobehavioural mechanisms of reward and motivation. Curr. Opin. Neurobiol. 6, 228-236.

Roberts, R. C., Harrison, M. B., Francis, S. M., and Wiley, R. G. (1993). Differential effects of suicide transport lesions of the striatonigral or striatopallidal pathways on subsets of striatal neurons. Exp. Neurol. 124, 242-252.

Roseberry, A. G., Liu, H., Jackson, A. C., Cai, X., and Friedman, J. M. (2004). Neuropeptide Y-mediated inhibition of proopiomelanocortin neurons in the arcuate nucleus shows enhanced desensitization in ob/ob mice. Neuron 41, 711-722.

Saka, E., Iadarola, M., Fitzgerald, D. J., and Graybiel, A. M. (2002). Local circuit neurons in the striatum regulate neural and behavioral responses to dopaminergic stimulation. Proc. Natl. Acad. Sci. U.S.A. 99, 9004-9009.

Sandberg, K., Hanin, I., Fisher, A., and Coyle, J. T. (1984). Selective cholinergic neurotoxin: AF64A's effects in rat striatum. Brain Res. 293, 49-55.

Sano, H., Yasoshima, Y., Matsushita, N., Kaneko, T., Kohno, K., Pastan, I., and Kobayashi, K. (2003). Conditional ablation of striatal neuronal types containing dopamine D2 receptor disturbs coordination of basal ganglia function. J. Neurosci. 23, 9078-9088.

Schaefer, A., Sampath, S. C., Intrator, A., Min, A., Gertler, T. S., Surmeier, D. J., Tarakhovsky, A., and Greengard, P. (2009). Control of cognition and adaptive behavior by the GLP/G9a epigenetic suppressor complex. Neuron 64, 678-691.

Schiffmann, S. N., and Vanderhaegen, J. J. (1993). Adenosine A2 receptors regulate the gene expression of striatopallidal and striatonigral neurons. J. Neurosci. 13, 1080-1087.

Shen, W., Flajolet, M., Greengard, P., and Surmeier, D. J. (2008). Dichotomous dopaminergic control of striatal synaptic plasticity. Science 321, 848-851.

Shen, W., Tian, X., Day, M., Ulrich, S., Tkatch, T., Nathanson, N. M., and Surmeier, D. J. (2007). Cholinergic modulation of Kir2 channels selectively elevates dendritic excitability in striatopallidal neurons. Nat. Neurosci. $10,1458-1466$.
Shuen, J. A., Chen, M., Gloss, B. and Calakos, N. (2008). DrdlatdTomato BAC transgenic mice for simultaneous visualization of medium spiny neurons in the direct and indirect pathways of the basal ganglia. J. Neurosci. 28, 2681-2685.

Sohal, V. S., Zhang, F., Yizhar, O., and Deisseroth, K. (2009). Parvalbumin neurons and gamma rhythms enhance cortical circuit performance. Nature 459, 698-702.

Soriano, P. (1999). Generalized lacZ expression with the ROSA26 Cre reporter strain. Nat. Genet.21,70-71.

Tanahira, C., Higo, S., Watanabe, K., Tomioka, R., Ebihara, S., Kaneko, T., and Tamamaki, N. (2009). Parvalbumin neurons in the forebrain as revealed by parvalbumin-Cre transgenic mice. Neurosci. Res. 63 213-223.

Tecuapetla, F., Koós, T., Tepper, J. M., Kabbani, N., and Yeckel, M. F. (2009). Differential dopaminergic modulation of neostriatal synaptic connections of striatopallidal axon collaterals. J. Neurosci. 29, 8977-8990.

Tepper, J. M., Abercrombie, E. D., and Bolam, J. P. (2007). Basal ganglia macrocircuits. Prog. Brain Res. 160 3-7.

Tepper, J. M., and Bolam, J. P. (2004). Functional diversity and specificity of neostriatal interneurons. Curr. Opin. Neurobiol. 14, 685-692.

Valjent, E., Bertran-Gonzalez, J., Hervé, D., Fisone, G., and Girault, J. (2009). Looking $\mathrm{BAC}$ at striatal signaling: cell-specific analysis in new transgenic mice. Trends Neurosci. 32, 538-547.

Vallone, D., Pignatelli, M., Grammatikopoulos, G., Ruocco, L., Bozzi, Y., Westphal, H., Borrelli, E., and Sadile, A. G. (2002). Activity, nonselective attention and emotionality in dopamine D2/D3 receptor knockout mice. Behav. Brain Res. 130, 141-148.

van den Pol, A. N., Yao, Y., Fu, L., Foo, K., Huang, H., Coppari, R., Lowell, B. B., and Broberger, C. (2009). Neuromedin B and gastrin-releasing peptide excite arcuate nucleus neuropeptide $\mathrm{Y}$ neurons in a novel transgenic mouse expressing strong Renilla green fluorescent protein in NPY neurons. J. Neurosci. 29, 4622-4639.

Wang, Z., Kai, L., Day, M., Ronesi, J., Yin, H. H., Ding, J., Tkatch, T., Lovinger, D. M., and Surmeier, D. J. (2006). Dopaminergic control of corticostriatal long-term synaptic depression in medium spiny neurons is mediated by cholinergic interneurons. Neuron 50, 443-452.
Weiner, D. M., Levey, A. I., Sunahara, R. K., Niznik, H. B., O’Dowd, B. F., Seeman, P., and Brann, M. R. (1991). D1 and D2 dopamine receptor mRNA in rat brain. Proc. Natl. Acad. Sci. U.S.A. 88, 1859-1863.

Wiley, R. G., Oeltmann, T. N., and Lappi, D. A. (1991). Immunolesioning: selective destruction of neurons using immunotoxin to rat NGF receptor. Brain Res. 562, 149-153.

Witten, I. B., Lin, S., Brodsky, M., Prakash, R., Diester, I., Anikeeva, P., Gradinaru, V., Ramakrishnan, C., and Deisseroth, K. (2010). Cholinergic interneurons control local circuit activity and cocaine conditioning. Science 330, 1677-1681.

Ye, H., Daoud-El Baba, M., Peng, R.-W., and Fussenegger, M. (2011). A synthetic optogenetic transcript device enhances blood-glucose homeostasis in mice. Science 332, 1565-1568.

Young, W., and Bonner, T. (1986). Mesencephalic dopamine neurons regulate the expression of neuropeptide mRNAs in the rat forebrain. Proc. Natl. Acad. Sci. U.S.A. 83, 9827-9831.

Zachariou, V., Bolanos, C. A., Selley, D. E., Theobald, D., Cassidy, M. P., Kelz, M. B., Shaw-Lutchman, T., Berton, O., Sim-Selley, L. J., Dileone, R. J., Kumar, A., and Nestler, E. J. (2006) An essential role for DeltaFosB in the nucleus accumbens in morphine action. Nat. Neurosci. 9, 205-211.

Zhang, F., Wang, L. P., Brauner, M. Liewald, J. F., Kay, K., Watzke, N., Wood, P. G., Bamberg, E., Nagel, G., Gottschalk, A., and Deisseroth, K. (2007). Multimodal fast optical interrogation of neural circuitry. Nature 446, 633-639.

Conflict of Interest Statement: The authors declare that the research was conducted in the absence of any commercial or financial relationships that could be construed as a potential conflict of interest.

Received: 26 May 2011; paper pending published: 17 June 2011; accepted: 03 July 2011; published online: 15 July 2011.

Citation: Durieux PF, Schiffmann SN and de Kerchove d'Exaerde A (2011) Targeting neuronal populations of the striatum. Front. Neuroanat. 5:40. doi: 10.3389/fnana.2011.00040

Copyright ๑ 2011 Durieux, Schiffmann and de Kerchove d'Exaerde. This is an open-access article subject to a nonexclusive license between the authors and Frontiers Media SA, which permits use, distribution and reproduction in other forums, provided the original authors and source are credited and other Frontiers conditions are complied with. 